\title{
Pain-related fear and functional recovery in sciatica: results from a 2-year observational study
}

This article was published in the following Dove Press journal:

Journal of Pain Research

31 October 2016

Number of times this article has been viewed

\section{AJ Haugen' \\ L Grøvle' \\ J Brox ${ }^{2}$ \\ B Natvig ${ }^{3}$ \\ M Grotle}

'Department of Rheumatology, Østfold Hospital Trust, Grålum, ${ }^{2}$ Department of Physical Medicine and Rehabilitation, Division for Neuroscience, Oslo University Hospital, ${ }^{3}$ Department of General Practice, Institute of Health and Society, University of Oslo, ${ }^{4}$ FORMI (Communication Unit for Musculoskeletal Disorders), Division of Neuroscience, Oslo University Hospital, Oslo, Norway
Correspondence: AJ Haugen Department of Rheumatology, Sykehuset Østfold, Postboks 300, 1714 Grålum, Norway

Tel +4791193452

Fax +4769866401

Email annhau@so-hf.no
Objectives: The purpose of this study was to explore the associations between pain-related fear, pain disability, and self-perceived recovery among patients with sciatica and disk herniation followed up for 2 years.

Patients and methods: Pain-related fear was measured by the Tampa Scale for Kinesiophobia (TSK) and the Fear-Avoidance Beliefs Questionnaire-Physical Activity (FABQ-PA) subscale. Disability was measured by the Maine-Seattle Back Questionnaire. At 2 years, patients reported their sciatica/back problem on a global change scale ranging from completely gone to much worse. No specific interventions regarding pain-related fear were provided.

Results: Complete data were obtained for 372 patients. During follow-up, most patients improved. In those who at 2 years were fully recovered $(n=66)$, pain-related fear decreased substantially. In those who did not improve $(n=50)$, pain-related fear remained high. Baseline levels of pain-related fear did not differ significantly between those who were fully recovered and the rest of the cohort. In the total cohort, the correlation coefficients between the 0-2-year change in disability and the changes in the TSK and the FABQ-PA were 0.33 and 0.38 , respectively. In the adjusted regression models, the $0-2$-year change in pain-related disability explained $15 \%$ of the variance in the change in both questionnaires.

Conclusion: Pain-related fear decreased substantially in patients who recovered from sciatica and remained high in those who did not improve. Generally, the TSK and the FABQ-PA yielded similar results. To our knowledge, this is the first study that has assessed pain-related fear in patients who recover from sciatica.

Keywords: kinesiophobia, fear-avoidance, recovery

\section{Introduction}

The fear-avoidance model is a theoretical framework proposed to explain why some patients develop persistent disability following an experience of acute low back or sciatic pain. ${ }^{1}$ A central concept of this framework is fear of pain. It suggests that painrelated fear may lead to avoidance of physical activity or movements that aggravate or provoke the pain, trapping patients into a downward spiral of increasing disability and dysfunction. ${ }^{2,3}$ In contrast, if the pain experience is perceived in a nonthreatening manner, patients will confront and deal with it adaptively, thereby leading to recovery. ${ }^{4}$ However, the fear-avoidance model does not fully explain which mechanisms are involved when patients recover and exactly what forms of confrontation might be adaptive. ${ }^{3}$ Little attention has been given to what happens to pain-related fear in patients who recover from pain disability. 
From a clinical standpoint, it is reasonable to expect that when pain disability improves, either spontaneously or due to effective treatment, pain-related fear will diminish. However, few studies have explored pain-related fear over time, and almost no data exist on patients who recover. Grotle et $\mathrm{al}^{5}$ followed an acute ( $<3$ weeks) and a chronic ( $>3$ months) cohort of patients with low back pain who reported similar levels of pain-related fear at baseline. In the acute cohort, in which pain and disability rapidly improved, pain-related fear diminished. In the chronic cohort, levels of pain and disability remained high, and pain-related fear did not diminish. Generally, pain-related fear has been shown to be more strongly related to self-reported disability than to pain intensity. 6,7

Among patients with low back pain, those with radiating pain in the leg, ie, sciatica, report more disability than those without radiating pain. ${ }^{8,9}$ Prospective studies indicate that a substantial number of patients with sciatica will improve within 1-2 years. ${ }^{10,11}$ Thus, sciatica might be a useful condition to study the associations of pain-related fear with disability and self-perceived recovery. To our knowledge, no longitudinal studies on pain-related fear have been performed in sciatica.

A challenge in investigating the mechanisms involved in the fear-avoidance model is how to assess pain-related fear. Several questionnaires exist, all measuring somewhat different aspects, but it is not known whether one is more suitable than the others. ${ }^{12}$ The two most commonly used are the Tampa Scale for Kinesiophobia (TSK) ${ }^{13}$ and the FearAvoidance Beliefs Questionnaire (FABQ). ${ }^{14}$ The TSK aims to measure kinesiophobia, meaning fear of movement and (re)injury; the FABQ includes one subscale to measure fear regarding physical activity (FABQ-PA).

The purpose of the present study was to follow up patients with sciatica for 2 years in order to explore how pain-related fear evolves over time and its relationship with both pain disability and self-perceived recovery. We hypothesized that pain-related fear would decrease in patients improving from their sciatica and remain high or would increase in those who did not improve. Due to the uncertainty as to measuring pain-related fear, we applied both the FABQ-PA and the TSK.

\section{Patients and methods Study population}

This was a 2-year follow-up study of patients with sciatica and disk herniation who had been referred to a back clinic in four hospitals in southeast Norway. Details have been presented elsewhere. ${ }^{15,16}$ The inclusion criteria were age
$>18$ years and radiating pain in the leg below the knee or paresis caused by a magnetic resonance imaging- or computed tomography-verified disk herniation at the corresponding level and side. The exclusion criteria included pregnancy, tumor, infection, prior surgery at the affected disk level, and inability to communicate in written Norwegian.

\section{Procedures}

Patients were invited to participate in the study by the clinical staff and received treatment as usual. The consultation included information about the condition and general advice to stay active and use pain medication if necessary. No specific interventions regarding pain-related fear were given. In patients with severe symptoms, surgery was performed at the discretion of the individual surgeon. At inclusion, patients completed a comprehensive questionnaire. Patients were followed up by questionnaires sent by mail at 1 year and 2 years.

\section{Measurements}

Pain-related fear was measured using the TSK and the FABQPA. A validated Norwegian TSK version containing 13 items and four response categories (strongly disagree, disagree, agree, and strongly agree) was used. ${ }^{17}$ The sum score ranges from 13 to 52; higher scores indicate a greater degree of kinesiophobia. In this study, we subtracted 13 from the sum giving a total score range of $0-39$. The FABQ-PA comprises four items, each of which is rated on a 7-point scale using verbal responses ranging from completely disagree $(0)$ to completely agree (6). This gives a possible score of $0-24$; a higher score indicates more fear-avoidance beliefs. ${ }^{18}$

Pain-related disability was measured by the MaineSeattle Back Questionnaire. The Maine-Seattle Back Questionnaire is an abbreviated version of the Patrick-modified 23-item Roland-Morris Disability Questionnaire designed for patients with sciatica and lumbar spinal stenosis. ${ }^{19,20}$ It contains 12 items of impairment and activity limitations due to leg or back pain within the same day. Each item is scored as yes (1) or no (0), yielding a possible score of $0-12$; higher scores indicate greater disability. At 2 years, patients reported their sciatica/back problem on a global change scale of seven possible verbal responses (completely gone, much better, better, a little better, no change, a little worse, and much worse). Those who reported completely gone were categorized as recovered, and those who reported no change, a little worse, and much worse were categorized as no change/worse. 


\section{Analyses}

The associations between pain-related fear and disability were analyzed by standardized response means (SRMs), correlation (Pearson's $r$ ), and multivariate linear regression. The change scores of the variables were calculated as the scores at 2 years subtracted from the scores at baseline. SRMs were calculated by dividing the change scores by the SD of the change. ${ }^{21}$ Linear regression models were performed using changes in the TSK and the FABQ-PA as dependent variables and change in disability as the independent variable. The models were adjusted for age, sex, smoking, educational level, baseline pain-related fear, and baseline disability. Collinearity was assessed by the variance inflation factor; values $<2.5$ were considered acceptable. ${ }^{22}$ Differences in pain-related fear at baseline were analyzed by the MannWhitney $U$ test; $P$-values $<0.05$ were considered significant. Missing items in the questionnaires were substituted with the arithmetic mean of values from the available items. ${ }^{23}$ All data analyses were performed using SPSS version 20.0 (IBM Corporation, Armonk, NY, USA).

\section{Ethics}

The study protocol was approved by the Regional Committee for Medical Research Ethics, Oslo, Norway, and the Ombudsman for Privacy in Research at the Norwegian Social Science Data Services. All patients received both written and oral information about the study before participation and gave informed signed consent.

\section{Results}

In total, 466 patients were included in the study, of whom $86(18.5 \%)$ patients did not respond at 2 years. Another three patients did not complete the TSK, and five patients did not complete the FABQ at baseline or at 2 years, giving complete data for 372 patients. Compared with those who completed the 2-year follow-up, the group of nonresponders was significantly younger, including more current smokers and fewer persons who were married/cohabitants. The baseline characteristics are shown in Table 1. In total, 117 (31\%) patients received disk surgery.

Generally, disability decreased substantially during follow-up. Pain-related fear also decreased but to a lesser degree (Figure 1 and Table 1). Table 2 shows the scores for pain-related fear and disability at baseline, 1 year, and 2 years, according to perceived global change at 2 years. In total, 66 patients reported their sciatica/back problem to be completely gone and were categorized as recovered. A total of 50 patients were categorized as no change/worse:
Table I Demographic and clinical characteristics at baseline, I year, and 2 years

\begin{tabular}{|c|c|c|c|}
\hline Characteristic & Baseline & I year & 2 years \\
\hline Males, n (\%) & $209(56)$ & - & - \\
\hline Age, years & $44.6(I I .3)$ & - & - \\
\hline Education, years & $13(3)$ & - & - \\
\hline Current smoker, n (\%) & $150(4 \mid)$ & - & - \\
\hline Married/cohabitant, n (\%) & $280(76)$ & - & - \\
\hline $\begin{array}{l}\text { Working full time, no } \\
\text { sick leave, } \mathrm{n}(\%)\end{array}$ & $76(20)$ & - & - \\
\hline First sciatica episode, n (\%) & $169(46)$ & - & - \\
\hline $\begin{array}{l}\text { Duration current episode } \\
<3 \text { months, n (\%) }\end{array}$ & $160(43)$ & - & - \\
\hline $\begin{array}{l}\text { Duration back problems } \\
>1 \text { year, } \mathrm{n}(\%)\end{array}$ & $259(70)$ & - & - \\
\hline Leg pain ${ }^{\mathrm{a}}$ & $63(28)$ & $26(28)$ & $23(27)$ \\
\hline Back pain $^{\mathrm{a}}$ & $42(30)$ & $28(27)$ & $25(24)$ \\
\hline Pain-related disability ${ }^{\mathrm{b}}$ & $8(3)$ & $4(3)$ & $4(3)$ \\
\hline TSK & $14(7)$ & II (7) & II (8) \\
\hline FABQ-PA & $12(5)$ & $9(6)$ & $8(6)$ \\
\hline
\end{tabular}

Notes: Values are mean (SD) if not stated otherwise. ${ }^{2}$ Visual analog scale (0-100). bMaine-Seattle back questionnaire (0-12).

Abbreviations: FABQ-PA, Fear-Avoidance Beliefs Questionnaire-Physical Activity (0-24); TSK, Tampa Scale for Kinesiophobia (0-39); SD, standard deviation; -, data not available.

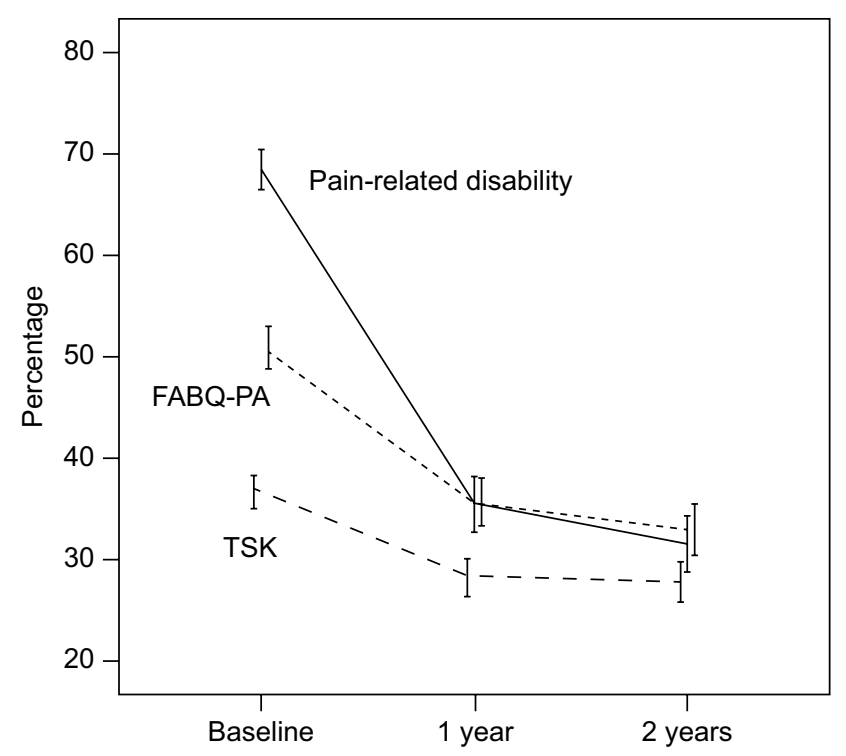

Figure I Pain-related fear and disability during 2 years follow-up.

Notes: Values are expressed as a percentage of the original scale. Error bars represent $95 \% \mathrm{Cl}$.

Abbreviations: $\mathrm{Cl}$, confidence interval; FABQ-PA, Fear-Avoidance Beliefs Questionnaire-Physical Activity; TSK, Tampa Scale for Kinesiophobia.

no change ( $\mathrm{n}=31)$, a little worse $(\mathrm{n}=11)$, and much worse $(n=8)$. In the patients who were recovered, the baseline scores on the TSK and the FABQ-PA did not differ significantly from the rest of the cohort. At 2 years, 16 (24\%) of the recovered patients reported the lowest possible score on the TSK and 33 (50\%) patients reported the lowest possible score on the FABQ-PA. In the no change/worse 
Table 2 Mean (SD) scores at baseline, I year, and 2 years with 0-2-year change and SRM according to patients' global perceived change at 2 years

\begin{tabular}{|c|c|c|c|c|c|}
\hline Characteristic & Baseline & I year & 2 years & $0-2$ year change & 0-2 year SRM \\
\hline \multicolumn{6}{|l|}{ Pain-related fear } \\
\hline \multicolumn{6}{|l|}{ TSK } \\
\hline Recovered $(n=66)$ & $12.7(5.6)$ & $6.2(5.8)$ & $5.9(5.8)$ & $6.7(6.0)$ & 1.12 \\
\hline Much better $(n=|5|)$ & $13.6(6.9)$ & $10.5(6.9)$ & $10.5(6.9)$ & $3.1(5.8)$ & 0.54 \\
\hline Better $(n=57)$ & $13.6(6.3)$ & II.4 (6.5) & II.2(7.4) & $2.4(6.8)$ & 0.35 \\
\hline A little better $(n=48)$ & $16.9(7.6)$ & $14.2(8.5)$ & $14.5(7.7)$ & $2.4(5.8)$ & 0.41 \\
\hline No change/worse $(n=50)$ & $15.2(8.0)$ & I4.4 (7.8) & $14.6(8.0)$ & $0.7(5.6)$ & 0.12 \\
\hline \multicolumn{6}{|l|}{ FABQ-PA } \\
\hline Recovered $(n=66)$ & $11.9(5.4)$ & $5.1(5.5)$ & $3.6(4.8)$ & $8.3(5.9)$ & 1.41 \\
\hline Much better $(n=|5|)$ & $11.9(5.0)$ & $8.4(5.7)$ & $7.3(5.3)$ & $4.5(5.8)$ & 0.77 \\
\hline Better $(n=57)$ & I I.6 (5.4) & $8.4(4.6)$ & $9.0(5.6)$ & $2.6(5.9)$ & 0.44 \\
\hline A little better $(n=48)$ & $12.4(5.9)$ & $10.7(6.5)$ & $10.1(6.0)$ & $2.3(5.3)$ & 0.42 \\
\hline No change/worse $(n=50)$ & $12.6(6.5)$ & II.7 (5.9) & $11.9(6.3)$ & $0.7(5.2)$ & 0.14 \\
\hline \multicolumn{6}{|l|}{ Pain-related disability } \\
\hline Recovered $(n=66)$ & $7.9(2.5)$ & $1.6(2.7)$ & $0.6(1.2)$ & $7.3(2.6)$ & 2.76 \\
\hline Much better $(n=|5|)$ & $7.9(2.5)$ & $3.1(2.7)$ & $2.6(2.2)$ & $5.3(2.8)$ & 1.86 \\
\hline Better $(n=57)$ & $8.4(2.7)$ & $5.5(2.8)$ & $5.2(2.8)$ & $3.2(3.4)$ & 0.94 \\
\hline A little better $(n=48)$ & $8.6(2.9)$ & $6.5(3.2)$ & $6.4(2.7)$ & $2.2(2.3)$ & 0.94 \\
\hline No change/worse $(n=50)$ & $8.3(2.5)$ & $6.7(2.8)$ & $7.5(2.7)$ & $0.8(2.5)$ & 0.32 \\
\hline
\end{tabular}

Note: Maine-Seattle Back Questionnaire (0-12).

Abbreviations: FABQ-PA, Fear-Avoidance Beliefs Questionnaire-Physical Activity (0-24); SD, standard deviation; SRM, standardized response mean; TSK, Tampa Scale for Kinesiophobia (0-39).

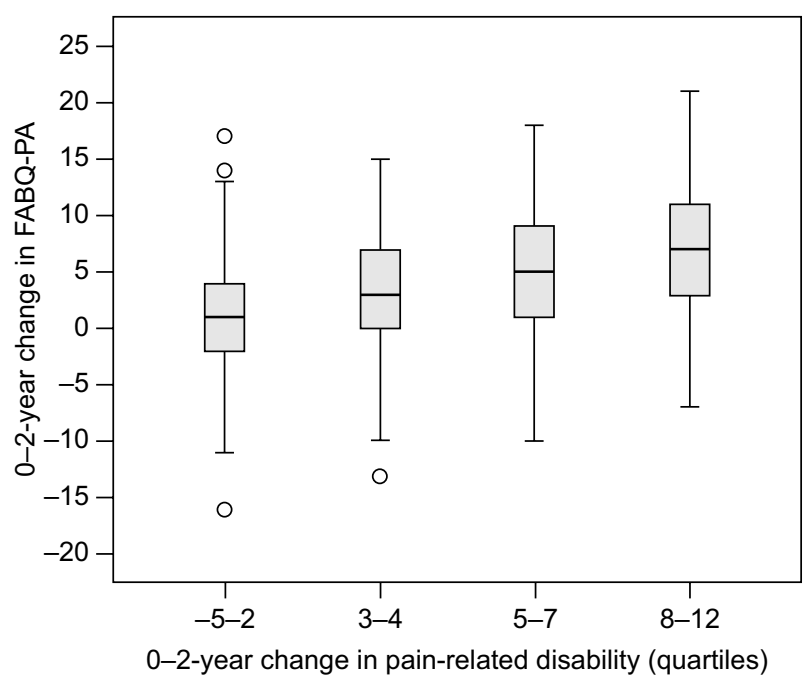

Figure 2 0-2-year change in the FABQ-PA according to change in pain-related disability.

Abbreviation: FABQ-PA, Fear-Avoidance Beliefs Questionnaire-Physical Activity

group, the pain-related fear scores were about the same at 2 years as at baseline.

The correlation coefficients between the $0-2$-year change in disability and the changes in the TSK and the FABQ-PA were 0.33 and 0.38 , respectively. Figures 2 and 3 indicates a linear relationship between disability and the two measures of pain-related fear.

Results of the multivariate regression analyses using the change in TSK and the change in FABQ-PA as dependent

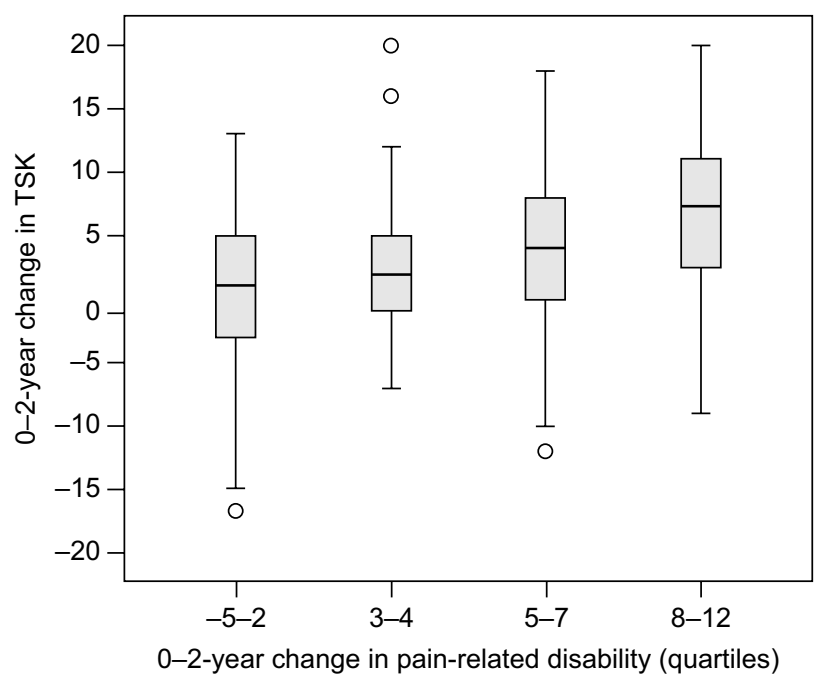

Figure 3 0-2-year change in the TSK according to change in pain-related disability. Abbreviation: TSK, Tampa Scale for Kinesiophobia.

variables are shown in Tables 3 and 4. In both models, the change in disability was significantly associated with the change in pain-related fear. Adding the change in disability increased the explained variance $\left(R^{2}\right)$ of the TSK change model from $13.8 \%$ to $29 \%$ and the FABQ-PA change model from $24.3 \%$ to $39.7 \%$. Age, sex, or smoking status was significantly associated with the outcomes. Education was significantly associated with the change in the TSK but not in the FABQ-PA. The correlation coefficient of the change in the 
Table 3 Linear regression on the 0 -2-year change in FABQ-PA

\begin{tabular}{llll}
\hline Variables & B & $\mathbf{9 5 \%} \mathbf{C l}$ & $\mathbf{P}$ \\
\hline Age & -0.04 & $-0.08,0.01$ & 0.11 \\
Female sex & 0.67 & $-0.36,1.69$ & 0.20 \\
Current smoking & -0.14 & $-1.20,0.92$ & 0.79 \\
Education (years) & 0.08 & $-0.10,0.26$ & 0.37 \\
Baseline FABQ-PA (0-24) & 0.59 & $0.49,0.69$ & $<0.00$ I \\
Baseline pain-related disability (0-12) & -0.63 & $-0.86,-0.40$ & $<0.00$ I \\
0-2 year change pain-related disability & 0.79 & $0.63,0.95$ & $<0.00$ I
\end{tabular}

Note: Maine-Seattle Back Questionnaire.

Abbreviations: $\mathrm{Cl}$, confidence interval; FABQ-PA, Fear-Avoidance Beliefs Questionnaire-Physical Activity.

Table 4 Linear regression on the $0-2$-year change in TSK

\begin{tabular}{llll}
\hline Variables & B & $\mathbf{9 5 \% ~ C l}$ & $\boldsymbol{P}$ \\
\hline Age & 0.00 & $-0.05,0.05$ & 0.88 \\
Female sex & 0.83 & $-0.29,1.96$ & 0.15 \\
Current smoking & 1.01 & $-0.16,2.18$ & 0.09 \\
Education, years & 0.20 & $0.01,0.40$ & 0.04 \\
Baseline TSK (0-39) & 0.37 & $0.29,0.45$ & $<0.00$ I \\
Baseline pain-related disability ${ }^{\mathrm{a}}(0-12)$ & -0.52 & $-0.77,-0.26$ & $<0.00$ I \\
0-2 year change pain-related disability & 0.80 & $0.62,0.99$ & $<0.00$ I
\end{tabular}

Note: aMaine-Seattle Back Questionnaire.

Abbreviations: $\mathrm{Cl}$, confidence interval; TSK, Tampa Scale of Kinesiophobia.

TSK and the change in the FABQ-PA was 0.45 . Generally, the SRMs of the FABQ-PA were somewhat larger than those of the TSK (Table 2). In those who were recovered, the SRMs of the FABQ-PA and the TSK were 1.41 and 1.12 , respectively.

\section{Discussion}

This study shows that pain-related fear decreased substantially in patients who at 2 years of follow-up recovered from sciatica. In those who did not improve, pain-related fear remained high but did not increase, compared with the levels at baseline. In adjusted regression models, the change in pain-related disability explained only $15 \%$ of the variance in the changes of both the TSK and the FABQ-PA. To our knowledge, this is the first study that has assessed pain-related fear longitudinally in patients with sciatica.

The patients who were fully recovered at 2 years reported very low levels of pain-related fear even below the corresponding values in the acute cohort in the study of Grotle et al. ${ }^{5}$ In the general population, pain-related fear has been assessed by rephrased items of the FABQ-PA ${ }^{24}$ and the TSK ${ }^{25}$ in order to make it possible for people without pain to complete them. Although different settings and questionnaire versions hamper direct comparisons, pain-free subjects in the general population seem to report more pain-related fear than those who fully recovered from sciatica in the present study. In a recent Finnish population study using the original wordings of the TSK, a subsample of healthy subjects also reported more pain-related fear than the recovered patients in our cohort. ${ }^{26}$

One may speculate whether the reduction in pain-related fear was simply a consequence of patients recovering from their sciatica. The observational design of this study precludes any inferences either of causality or of the direction of pathways in the fear-avoidance model. It is also possible that recovery was a result of improved coping strategies or confrontational attitudes as hypothesized in the model. However, it has been questioned whether the proposed directionality of pathways, especially the sequencing of pain severity in the cycle, is always true. ${ }^{27}$ Using path analyses in two prospective studies, Gheldof et $\mathrm{al}^{7}$ reported that painrelated fear may be better conceived of as a consequence of pain severity, rather than as an antecedent. In their study, pain severity at baseline strongly predicted both pain-related fear and disability at follow-up. Though no certain conclusions can be drawn, we would suggest that the improvements in pain-related fear in the present study were mainly a product of excellent clinical outcome results, supporting Gheldof et al's assumption. Interestingly, baseline levels of pain-related fear did not differ significantly between those who were recovered at 2 years and the rest of the cohort. Thus, it is unlikely that the recovered group consisted of individuals inherently low in the fear of pain.

In the regression models, the change in disability explained relatively little of the variance in the two painrelated fear measures. For patients who improved from their sciatica, the amount of change in the FABQ-PA, assessed by the SRM, was somewhat larger than that of the TSK; however, overall, the two measures yielded similar results. In a recent review, Wertli et al ${ }^{28}$ did not find evidence for recommending the use of the FABQ or the TSK over the other when used as a predictor of nonspecific low back pain. One challenge in the use of the TSK is the existence of several versions, which are not directly comparable. In the present study, we used the Norwegian validated 13 -item version without the original four negatively phrased items. ${ }^{17}$ To improve readability, we modified the total score range from $13-52$ to $0-39$.

In contrast to the present study on sciatica and disk herniation, previous research on pain-related fear has focused on painful conditions of unknown cause, such as nonspecific low back pain ${ }^{28}$ and fibromyalgia. ${ }^{29}$ Regarding longitudinal associations, our results suggest that it does not seem to matter whether the condition can be biomedically explained or not. The correlations observed between the changes in pain-related fear and the changes in disability in the present study are in-line with previous findings on nonspecific low 
back pain. Grotle et $\mathrm{al}^{5}$ found correlation coefficients of 0.39 and 0.41 between the 1-year change in the FABQ-PA and disability, as assessed by the Oswestry Disability Index, in patients with acute and chronic low back pain, respectively. Costa et $\mathrm{al}^{30}$ reported a correlation coefficient of 0.40 between the 1-year change in the TSK and the 1-year change in the Roland-Morris Disability Questionnaire in chronic low back pain. In a meta-analysis of cross-sectional studies, the average sample size-weighted correlation between pain-related fear and disability was found to be $0.42 .{ }^{31}$ Lundberg et $\mathrm{al}^{32}$ found no difference in the levels of TSK between patients with specific and nonspecific low back pain.

In line with the guidelines for low back pain and sciatica, ${ }^{33,34}$ the patients in the present study were encouraged to stay active, but no standardized cognitive interventions or exercises were provided. For treatment of low back pain, there is some evidence that health care providers with a biomedical orientation may be more likely to advise patients to limit their work and physical activities. ${ }^{35,36}$ Because all patients in the present study had radicular pain corresponding to a disk herniation, the physicians and the physiotherapists may have focused more on a biomedical than a biopsychosocial explanatory model.

\section{Strengths and Limitations}

The main strengths of the present study were the large sample size, a high rate of follow-up, and the multicenter design enhancing the external validity of the results. During followup, most patients improved, providing an adequate setting for studying pain-related fear and recovery over time. However, the application of strict inclusion criteria renders the results valid only for patients who fulfill those criteria, ie, sciatic pain below the knee and paresis caused by a disk herniation at the corresponding level and side.

The limitations of this study are that we do not know about the information or other treatment suggestions that patients may have received during the study period. We also do not know whether sources external to this study might have influenced the participants' pain-related fear. We did not evaluate or measure pain-related fear in the clinical staff and health professionals involved in the study. The use of other instruments to measure pain-related fear, such as the Pain Anxiety Symptoms Scale ${ }^{37}$ and the Fear of Pain Questionnaire, ${ }^{38}$ might have given different results. ${ }^{12}$ The dropout rate at 2 years was $18.5 \%$, with nonresponders being significantly younger, more likely to be current smokers and less likely to be married/cohabitating than those who completed the 2-year follow-up. We cannot know how the loss to follow-up may have influenced the results, but in the regression analyses (Tables 3 and 4), age and smoking status were not significantly associated with the pain-related fear outcomes. Thus, we believe the effects of nonresponse are limited.

As of yet, the results of the present study have no direct implications for clinical practice. Further research should focus on disentangling the causal pathways of pain-related fear. So far, it has been considered an antecedent to pain disability and an obstacle to recovery. However, it may be equally possible that the causal chain runs in the opposite direction, ie, that pain-related fear is simply a consequence of pain severity. A clarification of these potentially conflicting explanations would be of major interest.

\section{Conclusion}

Our results demonstrate that pain-related fear, assessed by the TSK and the FABQ-PA, decreased substantially in patients who recovered from sciatica and remained high in those who did not improve. Generally, the two measures of pain-related fear yielded similar results.

\section{Acknowledgments}

The study was supported by a grant from the Southeastern Norway Regional Health Authority; no support was received from commercial sources.

\section{Author contributions}

All authors contributed toward data analysis, drafting and critically revising the paper and agree to be accountable for all aspects of the work.

\section{Disclosure}

The authors report no conflicts of interest in this work.

\section{References}

1. Lethem J, Slade PD, Troup JD, Bentley G. Outline of a fear-avoidance model of exaggerated pain perception-I. Behav Res Ther. 1983; 21(4):401-408

2. Vlaeyen JW, Linton SJ. Fear-avoidance and its consequences in chronic musculoskeletal pain: a state of the art. Pain. 2000;85(3):317-332.

3. Crombez G, Eccleston C, Van Damme S, Vlaeyen JW, Karoly P. Fearavoidance model of chronic pain: the next generation. Clin J Pain. 2012;28(6):475-483.

4. Pincus T, Smeets RJ, Simmonds MJ, Sullivan MJ. The fear avoidance model disentangled: improving the clinical utility of the fear avoidance model. Clin J Pain. 2010;26(9):739-746.

5. Grotle M, Vollestad NK, Brox JI. Clinical course and impact of fearavoidance beliefs in low back pain: prospective cohort study of acute and chronic low back pain: II. Spine. 2006;31(9):1038-1046.

6. Crombez G, Vlaeyen JW, Heuts PH, Lysens R. Pain-related fear is more disabling than pain itself: evidence on the role of pain-related fear in chronic back pain disability. Pain. 1999;80(1-2):329-339. 
7. Gheldof EL, Crombez G, Van den Bussche E, et al. Pain-related fear predicts disability, but not pain severity: a path analytic approach of the fear-avoidance model. Eur J Pain. 2010;14(8): 870.e1-870.e9.

8. Selim AJ, Ren XS, Fincke G, et al. The importance of radiating leg pain in assessing health outcomes among patients with low back pain. Results from the Veterans Health Study. Spine. 1998;23(4): $470-474$.

9. Hill JC, Konstantinou K, Egbewale BE, Dunn KM, Lewis M, van der Windt D. Clinical outcomes among low back pain consulters with referred leg pain in primary care. Spine. 2011;36(25):2168-2175.

10. Peul WC, van den Hout WB, Brand R, Thomeer RT, Koes BW; LeidenThe Hague Spine Intervention Prognostic Study Group. Prolonged conservative care versus early surgery in patients with sciatica caused by lumbar disc herniation: two year results of a randomised controlled trial. BMJ. 2008;336(7657):1355-1358.

11. Weinstein JN, Lurie JD, Tosteson TD, et al. Surgical vs nonoperative treatment for lumbar disk herniation: the Spine Patient Outcomes Research Trial (SPORT) observational cohort. JAMA. 2006;296(20):2451-2459.

12. Lundberg M, Grimby-Ekman A, Verbunt J, Simmonds MJ. Painrelated fear: a critical review of the related measures. Pain Res Treat. 2011;2011:494196.

13. Kori SH, Miller RP, Todd DD. Kinisophobia: a new view of chronic pain behavior. Pain Manag. 1990;3(1):35-43.

14. Waddell G, Newton M, Henderson I, Somerville D, Main CJ. A Fear-Avoidance Beliefs Questionnaire (FABQ) and the role of fearavoidance beliefs in chronic low back pain and disability. Pain. 1993;52(2):157-168.

15. Grovle L, Haugen AJ, Keller A, Natvig B, Brox JI, Grotle M. The bothersomeness of sciatica: patients' self-report of paresthesia, weakness and leg pain. Eur Spine J. 2010;19(2):263-269.

16. Haugen AJ, Grovle L, Brox JI, et al. Estimates of success in patients with sciatica due to lumbar disc herniation depend upon outcome measure. Eur Spine J. 2011;20(10):1669-1675.

17. Haugen AJ, Grovle L, Keller A, Grotle M. Cross-cultural adaptation and validation of the Norwegian version of the Tampa scale for kinesiophobia. Spine. 2008;33(17):E595-E601.

18. Grotle M, Brox JI, Vollestad NK. Reliability, validity and responsiveness of the fear-avoidance beliefs questionaire: methodological aspects of the Norwegian version. J Rehabil Med. 2006;38(6):346-353.

19. Atlas SJ, Deyo RA, van den Ancker M, Singer DE, Keller RB, Patrick DL. The Maine-Seattle back questionnaire: a 12-item disability questionnaire for evaluating patients with lumbar sciatica or stenosis: results of a derivation and validation cohort analysis. Spine. 2003;28(16): 1869-1876.

20. Grovle L, Haugen AJ, Keller A, Natvig B, Brox JI, Grotle M. Reliability, validity, and responsiveness of the Norwegian versions of the Maine-Seattle Back Questionnaire and the Sciatica Bothersomeness and Frequency Indices. Spine. 2008;33(21):2347-2353.

21. Cohen J. Statistical Power Analysis for the Behavioral Sciences. Vol. 2. Hillsdale, NJ: Lawrence Erlbaum Associates, Inc.; 1988.
22. Hair JF. Multivariate Data Analysis. 7th ed. Upper Saddle River: Prentice Hall; 2010.

23. Chavance M. Handling missing items in quality of life studies. Commun Stat Theory Methods. 2004;33(6):1371-1383.

24. Buer N, Linton SJ. Fear-avoidance beliefs and catastrophizing: occurrence and risk factor in back pain and ADL in the general population. Pain. 2002;99(3):485-491.

25. Houben RMA, Leeuw M, Vlaeyen JWS, Goubert L, Picavet HSJ. Fear of movement/injury in the general population: factor structure and psychometric properties of an adapted version of the Tampa Scale for Kinesiophobia. J Behav Med. 2005;28(5):415-424.

26. Koho P, Borodulin K, Kautiainen H, Kujala U, Pohjolainen T, Hurri H. Finnish version of the Tampa Scale of Kinesiophobia: reference values in the Finnish general population and associations with leisure-time physical activity. J Rehabil Med. 2015;47(3):249-255.

27. Asmundson GJ, Parkerson HA, Petter M, Noel M. What is the role of fear and escape/avoidance in chronic pain? Models, structural analysis and future directions. Pain Manag. 2012;2(3):295-303.

28. Wertli MM, Rasmussen-Barr E, Weiser S, Bachmann LM, Brunner F. The role of fear avoidance beliefs as a prognostic factor for outcome in patients with nonspecific low back pain: a systematic review. Spine J. 2014;14(5): 816.e4-836.e4.

29. Turk DC, Robinson JP, Burwinkle T. Prevalence of fear of pain and activity in patients with fibromyalgia syndrome. J Pain. 2004;5(9):483-490.

30. Costa Lda C, Maher CG, McAuley JH, Hancock MJ, Smeetsl RJ. Self-efficacy is more important than fear of movement in mediating the relationship between pain and disability in chronic low back pain. Eur J Pain. 2011;15(2):213-219.

31. Zale EL, Lange KL, Fields SA, Ditre JW. The relation between pain-related fear and disability: a meta-analysis. J Pain. 2013;14(10):1019-1030.

32. Lundberg M, Frennered K, Hagg O, Styf J. The impact of fear-avoidance model variables on disability in patients with specific or nonspecific chronic low back pain. Spine. 2011;36(19):1547-1553.

33. Koes BW, van Tulder MW, Peul WC. Diagnosis and treatment of sciatica BMJ. 2007;334(7607):1313-1317.

34. Lærum E, Brox JI, Storheim K et al. Nasjonale kliniske retningslinjer. Korsryggsmerter - med og uten nerverotaffeksjon. Oslo: FORMI, Formidlingsenheten for muskel- og skjelettlidelser/Sosial- og helsedirektoratet, 2007. www.formi.no. Accessed September 10, 2007.

35. Rainville J, Carlson N, Polatin P, Gatchel RJ, Indahl A. Exploration of physicians' recommendations for activities in chronic low back pain. Spine. 2000;25(17):2210-2220.

36. Darlow B, Fullen BM, Dean S, Hurley DA, Baxter GD, Dowell A. The association between health care professional attitudes and beliefs and the attitudes and beliefs, clinical management, and outcomes of patients with low back pain: a systematic review. Eur J Pain. 2012;16(1):3-17.

37. McCracken LM, Zayfert C, Gross RT. The Pain Anxiety Symptoms Scale: development and validation of a scale to measure fear of pain. Pain. 1992;50(1):67-73.

38. Hursey KG, Jacks SD. Fear of pain in recurrent headache sufferers. Headache. 1992;32(6):283-286
Journal of Pain Research

\section{Publish your work in this journal}

The Journal of Pain Research is an international, peer reviewed, open access, online journal that welcomes laboratory and clinical findings in the fields of pain research and the prevention and management of pain. Original research, reviews, symposium reports, hypothesis formation and commentaries are all considered for publication.
The manuscript management system is completely online and includes a very quick and fair peer-review system, which is all easy to use. Visit http://www.dovepress.com/testimonials.php to read real quotes from published authors. 